\title{
VIGOTSKI E LEONTIEV: RESSONÂNCIAS DE UM PASSADO
}

\author{
ELIZABETH TUNES \\ Professora do Programa de Pós-Graduação em Educação da Universidade de Braślia \\ bethtunes@globo.com \\ ZOIA PRESTES \\ Doutoranda do Programa de Pós-Graduação em Educação da Universidade de Brasília \\ 81629891z@gmail.com
}

\section{RESUMO}

O artigo trata do relacionamento entre Lev Semionovitch Vigotski e Aleksei Nikolaievitch Leontiev. Sabe-se que os dois trabalharam juntos ao longo dos anos 20 do século XIX e são considerados fundadores da teoria histórico-cultural da psicologia soviética, juntamente com Aleksandr Romanovitch Luria. Inicialmente, as autoras trazem informações a respeito da biografia e trajetória científica de L. S. Vigotski, fundamentando-as com fatos extraídos de diferentes fontes. O principal assunto abordado, o suposto rompimento ocorrido entre Vigotski e Leontiev, é examinado no artigo, escrito por descendentes de A. N. Leontiev, no qual são publicadas cartas originais de Leontiev e Vigostski. Ao final, as autoras apresentam uma entrevista realizada com o neto de Leontiev, professor Dimitri Leontiev.

LEONTIEV - VIGOTSKI - PSICOLOGIA - BIOGRAFIA

\section{ABSTRACT}

VYGOTSKY AND LEONTIEV: RESONANCES OF A PAST. This article addresses the relationship between Lev Semionovitch Vygotsky and Aleksei Nikolaievitch Leontiev. The two authors are known to have worked together throughout the 1920's and are considered the founders of the historical and cultural theory of Soviet psychology, along with Aleksandr Romanovitch Luria. Initially, information on the biography and scientific trajectory of L. S. Vygotsky is provided based on facts obtained from different sources. The main subject addressed, the supposed breach between Vygotsky and Leontiev, is examined in the article written by descendants of A. N. Leontiev, where original letters written by Leontiev and Vygotsky were published. Finally, there is an interview with Leontiev's grandson, professor Dimitri Leontiev.

LEONTIEV - VYGOTSKY - PSYCHOLOGY - BIOGRAPHIES 
Para saber como um pensador criou e inovou em seu campo de atuação é importante conhecer a época em que viveu, o contexto social e histórico do mundo e de seu país, seus círculos de amizade e de colaboradores, enfim, sua trajetória de vida. A ciência é uma atividade estritamente humana. Suas criações refletem a busca por respostas às indagações de um determinado período. Existe uma relação íntima entre o contexto histórico e a elaboração de teorias. Seria impossível avaliar a evolução de um pensamento fora do tempo, fora dos fatos, sem levar em conta o zeitgheist.

Essa tarefa, todavia, quase sempre está longe de ser fácil, simples e isenta de riscos. Isso vale, especialmente, para aqueles que viveram e criaram em épocas de fortes turbulências históricas e sociais. Esse é o caso de Lev Semionovitch Vigotski ( 1896-1934). Sua vida e carreira apresentam-nos, segundo as palavras de Kozulin (1990, p. 13), "uma notável e sugestiva qualidade literária, que amiúde lembra a vida dos heróis da literatura de Thomas Mann, Hermann Hesse ou Boris Pasternack", numa espécie de síntese dos temas fundamentais da vida intelectual do século $X X$.

Os primórdios de sua vida intelectual coincidem com a Revolução Socialista Russa e parte do período de sua produção acontece com o país imerso em uma terrível guerra civil. Ainda muito jovem, é acometido de tuberculose, doença de que vem a falecer em I I de junho de 1934, portanto, com 38 anos incompletos. Em seu curto período de vida trabalhou intensamente, deixando bastante desenvolvidas as bases de uma nova vertente teórica para o estudo psicológico do homem, denominada, no início, psicologia instrumental e, posteriormente e até os dias de hoje, psicologia histórico-cultural.

Apesar de ser considerado, hoje, um pensador que revolucionou a psicologia, antecipando em muitos anos questões fundamentais que são examinadas na atualidade e de ser, efetivamente, quem estabeleceu as bases de uma psicologia genuinamente soviética, foi um estrangeiro de sua época. Estrangeiro em dois sentidos. Conforme aponta Kozulin (1990, p. I 4), "os textos de Vigotski têm muito pouco a oferecer em matéria de respostas definitivas a enigmas científicos. Sua habilidade mais característica era a de transformar o que pareciam respostas a esses enigmas em questões novas e mais profundas". Todavia, essas questões somente foram reconhecidas por seus contemporâneos, décadas depois de formuladas. Esse é um primeiro sentido dado à palavra estrangeiro. O segundo, diz respeito à difusão de seu trabalho em seu próprio país. Sua 
Vigotski e Leontiev...

obra foi censurada e proibida na União Soviética entre meados dos anos trinta a meados da década de cinquenta do século passado, "o que significou que toda uma geração de psicólogos soviéticos cresceu com um conhecimento muito limitado de suas ideias" (Kozulin, 1990, p. 16).

Não foi sem percalços que suas obras chegaram até os dias de hoje. Alvos de críticas contundentes, muitos trabalhos seus tiveram destinos dramáticos. A autonomia de sua produção científica em relação aos preceitos ditados pelo governo instituído em seu país refletiu-se na integridade de suas obras.

Em 1996, foi publicada na Rússia a biografia de Vigotski escrita por sua filha, Guita Lvovna Vigodskaia e por Tatiana Mikhailovna Lifanova. O livro traz muitos detalhes desconhecidos, até então, sobre a sua trajetória. Guita relata que, ao elaborar a bibliografia dos trabalhos de seu pai, no início dos anos 70 , encontrou diversos números de revistas que publicaram artigos dele sem indicar as páginas correspondentes. Em seu lugar, havia um carimbo com os dizeres: "Retiradas de acordo com o Decreto sobre as deturpações pedológicas no sistema, do Comissariado do Povo para a Instrução".

Em 1955, Luria e Leontiev empreendem esforços para a publicação dos trabalhos de Vigotski. Mas a pedologia ainda pertencia ao vocabulário proibido. Então, Luria teve a ideia de substituir "pedologia" por "psicologia infantil". Assim foi feito e os textos começaram a ser editados e publicados.

Subsistindo, assim, na clandestinidade, não é de se estranhar que seus textos tenham sido violentados, tanto em seu país quanto fora dele. Muito do que chegou até nós brasileiros entre, aproximadamente, 1960 e o final do século passado, proveniente principalmente dos Estados Unidos, foram textos resumidos, reformados, adaptados, adulterados, o que, é claro, acarreta distorções e até mesmo deturpações das ideias do autor. Além do mais, isso torna penoso e difícil o trabalho de organização e publicação da obra completa de Vigotski, dada a necessidade de se realizar pesquisas minuciosas para que se possa fazer a destilação, separando o original do corrompido.

A biografia de Vigotski (Vigodskaia, Lifanova, 1996) é um registro importante para quem se dedica aos estudos sobre a teoria histórico-cultural. Os detalhes da trajetória do cientista estão descritos e fundamentados com documentos históricos, periódicos da época, cartas, bilhetes, relatos, entre outros. Por ter sido escrito pela filha de um pensador do porte de Vigotski, o livro não escapa do viés emotivo-afetivo, o que enriquece as páginas de uma 
vida breve, mas intensa. Além disso, ela traz, pela primeira vez, uma completa relação bibliográfica de todas as obras de Vigotski.

Do mesmo modo, obra, vida e carreira desse pensador são também cercadas de enigmas e informações desencontradas. Se até em relação a um dado simples como a cidade em que nasceu, há discrepâncias - diz-se que nasceu em Gomel (Kozulin, 1990, p.24), mas se diz também que nasceu em Orsha, cidade próxima a Minsk, capital da Bielo-Rússia (Luria, 1979; Luria, 1984; Levitin, 1980) -, é de se esperar que elas existam em aspectos mais fundamentais para a compreensão de suas ideias. Costuma-se afirmar que a carreira científica de Vigotski inicia-se em 1924, após a apresentação de um trabalho científico no Congresso Russo de Pedologia, Pedagogia Experimental e Psiconeurologia ( ${ }^{\circ}$ Congresso Russo de Psiconeurologia), realizado em Petrogrado, de 3 a 10 de janeiro. Todavia, há autores que discordam dessa afirmação (Blanck, 2003, larochevski, 2007). A filha Guita transcreve trecho de um certificado, expedido pelo Departamento da União dos Trabalhadores para a Instrução da cidade de Gomel, apresentado por Vigotski para fins de sua contratação pelo Instituto de Psicologia de Moscou, no qual se lê:

Ao longo de 5 anos, L .S. Vigotski lecionou nas escolas de $1^{\circ}$ e $2^{\circ}$ graus, em escolas técnicas, em escolas profissionalizantes de gráficos e metalúrgicos, nas escolas noturnas de Instrução Política para adultos, nos cursos de Educação Socialista de preparação de trabalhadores para a educação pré-escolar, nos cursos de verão de qualificação dos trabalhadores das escolas, na Faculdade para Operários, de Gomel, e em escolas... (Vigodskaia, Lifanova, 1996, p.68, tradução nossa)

larochevski, por sua vez, apresenta uma declaração escrita do próprio punho de Vigotski, que contém as seguintes informações:

Sobre as atividades científicas e de pesquisa: iniciei meu trabalho científico em 1917, após a conclusão do curso universitário. Organizei um gabinete de psicologia na Escola Técnica de Pedagogia onde realizei atividades de pesquisa. (larochevski, 2007, p.47)

No livro de Vigodskaia e Lifanova, no terceiro capítulo, denominado "Com os olhos da filha", é relatado um fato, pouco esclarecido, que diz respeito 
Vigotski e Leontiev...

ao "rompimento" entre Vigotski e Aleksei Nikolaievitch Leontiev. Aí se publicam, pela primeira vez, trechos de uma carta de Vigotski dirigida a Leontiev. Guita reproduzindo relatos de sua mãe, Rosa Smekhova, conta que Vigotski respondia a uma carta de Leontiev, que este redigira, "parece que de Kharkov" (p.3|6), endereçada a Luria. Conforme consta no livro, o teor da carta de Leontiev "parece" que continha algo do tipo: "Vigotski é uma etapa vencida, o ontem da psicologia", propondo a Luria trabalhar sem Vigotski. Inicialmente, Luria teria concordado, mas depois arrependeu-se e mostrou a carta a Vigotski, que vivenciou tudo com muito sofrimento, sentindo-se traído'.

Quando escrevia a biografia do pai, Guita Lvovna teve acesso aos arquivos da família de Leontiev onde estão guardadas cartas de Vigotski para Leontiev. Ela transcreve trechos de duas cartas, uma datada de II de julho de 1929 e outra de 2 de agosto de 19332. São dois documentos raros e importantes para os interessados em conhecer a vida de Vigotski. A carta de 1933 traz informações a respeito de seu suposto "rompimento" com Leontiev. Porém, a carta deste último, que teria desencadeado a resposta de Vigotski, era dada como desaparecida até a data da publicação do livro de Guita.

Tradicionalmente, no dia 5 de fevereiro, comemora-se o aniversário de Leontiev. Nessa ocasião, seus amigos se reunem para homenageá-lo. Em 2002, a filha adotiva de Luria, Elena, compareceu a uma dessas comemorações, levando um documento precioso que havia encontrado nos arquivos do pai: a carta de Leontiev a Vigotski que era dada como desaparecida. Essa carta foi entregue ao filho e ao neto de Leontiev, e datava de 5 de fevereiro de 1932. Estaria aí a chave para desvendar o "rompimento", cercado de mistérios, a que Guita se refere?

Aleksei Alekseevitch e Dmitri Alekseevitch, respectivamente, filho e neto de Aleksei Nikolaievitch Leontiev, publicaram um artigo em que transcrevem e comentam as cartas de Vigotski e Leontiev. Além disso, descrevem o contexto histórico, as circunstâncias e alguns fatos em torno da relação entre Leontiev e Vigotski. Apesar de elucidar alguns acontecimentos envolvendo os dois estudio-

I. O mesmo episódio é relatado por Guillermo Blanck em prefácio à edição brasileira de Psicologia pedagógica (Vigotski, 2003).

2. O texto da carta aqui referida, de 2 de agosto de 1933, é o mesmo que os Leontiev transcrevem em seu artigo e indicam ser datado de 7 de agosto de 1933. Para comparar, consultar Vigodskaia e Lifanova (1996, p.317) e o documento traduzido adiante. 
sos, muitos fatos ainda desafiam a nossa imaginação. E mais importante do que isso, as cartas transcritas no artigo revelam a profundidade do diálogo entre os dois pensadores, um verdadeiro debate de ideias. Vale também ressaltar que não há ainda uma apreciação da carta encontrada, de Leontiev a Vigotski, por parte de Guita Vigodskaia. O artigo dos Leontiev foi publicado, parcialmente, no livro de Leontiev, Leontiev e Sokolova (2005, p.48-54).

É esse importante documento, cuja tradução e publicação foram autorizadas pelo professor Dmitri Alekseevitch Leontiev, que apresentamos a seguir para todos os que se interessam pela história da psicologia soviética.

Além disso, transcrevemos trechos da entrevista que realizamos com o professor Dmitri, no Instituto de Psicologia da Universidade de Moscou. Os trechos selecionados dizem respeito ao episódio central tratado neste texto.

\section{ARTIGO DOCUMENTAL}

\section{O mito do rompimento: A. N. Leontiev e L. S. Vigotski, em 1932}

\section{A.A.Leontiev" e D.A.Leontiev"}

\section{Tradução: Zoia Prestes}

Um dos pontos mais discutidos e dolorosos da história da psicologia russa é a separação que ocorreu entre L. S. Vigotski e A. N. Leontiev e que refletiu na partida deste para Kharkov, onde ficou por muitos anos. Em Kharkov, A. N. Leontiev liderou concomitantemente vários subgrupos científicos e iniciou, junto com um grupo de jovens psicólogos que, posteriormente, recebeu o nome de Escola ou Grupo de Kharkov, pesquisas que levaram à formação das bases teóricas e experimentais da teoria psicológica geral da atividade, relacionada primeiramente ao nome de A. N. Leontiev.

A partida em si é um fato que apresenta pelo menos duas questões que são ativamente debatidas na literatura histórico-científica e memorialística.

* Aleksei Alekseevitch Leontiev (1935-2004), doutor em Filologia e em Psicologia, professor e membro da Academia de Ciência da Educação e filho de Aleksei Nikolaievitch Leontiev. É autor de vários livros em psicologia (N. da T.).

** Dmitri Alekseevitch Leontiev (1963-), doutor em Psicologia, professor da Faculdade de Psicologia da Universidade de Moscou, diretor do Instituto de Psicologia Existencial e da Criação, é autor de uma série de livros sobre psicologia existencial; é neto de Aleksei Nikolaievitch Leontiev (N. da T.). 
Vigotski e Leontiev...

A primeira questão é histórica; diz respeito aos motivos e às raízes dessa separação e indaga se ela foi um rompimento ou apenas um conflito. Os testemunhos são contraditórios e mitológicos. O próprio A. N. Leontiev, homem reservado, nunca mencionou qualquer divergência. A. R. Luria, em suas memórias, também nada menciona, assim como sua filha, Elena. $\bigcirc$ livro de Elena', por força das circunstâncias históricas, é muito mais detalhado do que a autobiografia semioficial do próprio Aleksandr Romanovitch². $\bigcirc$ mito mais amplamente difundido diz que os kharkovtchane ${ }^{* * *}$ recusaram determinantemente a herança teórica de Vigotski e se posicionaram contra a teoria "histórico-cultural". Segundo o mito, no início da década de 1930 , surgiu uma oposição científica e pessoal entre Vigotski e o Grupo de Kharkov, liderado por Leontiev. Sob a luz desse mito, a partida de A. N. Leontiev é tratada emotivamente como traição. Falamos de mito porque não existem quaisquer provas, claras ou veladas, de que houve inimizade ou competição entre Vigotski e Leontiev.

Particularmente, nesse espírito mitológico, a história do relacionamento entre Lev Semionovitch e Aleksei Nikolaievitch está descrita no livro sobre Vigotski, de G. L. Vigodskaia e T. M. Lifanova. Guita Lvovna conta que, segundo a mulher de Vigotski, provavelmente, no final de 1933 ou bem no início de 1934, Aleksei Nikolaievitch escreveu de Kharkov uma carta a Luria, que

...dizia algo do tipo que Vigotski é uma etapa ultrapassada, é o ontem da psicologia e propunha a Aleksandr Romanovitch trabalhar sem Vigotski. Aleksandr Romanovitch de início concordou, mas depois, pelo visto, pensou melhor, foi até meu pai (que nessa época não estava muito bem de saúde) e mostrou-lhe a carta. Vigotski sofreu muito com o ocorrido, tomando a atitude de Leontiev não só como uma traição pessoal, mas como uma traição em relação ao trabalho em comum e the escreveu uma carta agressiva... Penso que o sofrimento foi ainda maior quando Vigotski sentiu que tudo estava sendo feito não às claras,

E. Luria. Moi otets. Moskva: Gnozis, 1994 ( N. dos AA.).

2. A. R. Luria. Etapi proidennogo puti. Moskva: Izdatelstvo Moskovskogo Universiteta, 1982 (N. dos AA.)

**** Nome dado aos membros do Grupo de Kharkov (N. da T.) 
mas pelas costas... Não sei se meu pai e A. N. Leontiev encontraram-se após esse episódio, mas sei que a relação nunca foi restabelecida... ${ }^{3}$

Esse relato é incrível por vários motivos. Primeiramente, o caráter das relações de Vigotski com seus alunos é muito claro, pelo menos quanto ao que se vê em sua correspondência com Leontiev, o que tornaria impossível esse tipo de atitude atribuída a Leontiev. A ênfase da carta está exatamente no desejo, repetido várias vezes, de conversar sobre tudo, colocar as cartas na mesa, por mais doloroso que fosse. Prosseguindo, é improvável que o convite de Leontiev para trabalhar sem Vigotski tivesse sido endereçado exatamente a Luria: na carta citada, Aleksei Nikolaievitch critica severamente Aleksandr Romanovitch, principalmente no âmbito da relação deste último com a "psicologia cultural" (como se percebe pela carta de Vigotski, ele também compartilhava dessa avaliação). Finalmente, essa versão não se comprova não apenas pelas cartas transcritas mais adiante, incluindo as de Vigotski, como pelo desenrolar dos acontecimentos de que participaram Vigotski, Leontiev e Luria.

A segunda questão é puramente teórica: ainda hoje não há uma opinião única sobre até que ponto há continuidade entre as teorias de Vigotski e Leontiev. As bases teóricas da teoria da atividade, ou do enfoque da atividade, de A. N. Leontiev, inauguradas com os trabalhos realizados em Kharkov, foram formuladas, em primeira versão, no fim da década de 1930, quando Vigotski já havia falecido. Por isso, é impossível saber a opinião dele. As opiniões de Leontiev e de Luria eram idênticas: o enfoque da atividade não é uma teoria nova, mas um desenvolvimento natural das ideias de Vigotski; os dois, até o final de suas vidas, consideravam Vigotski o fundador e líder daquela corrente científica a que também se afiliavam. No entanto, o ímpeto de "subtrair" da teoria histórico-cultural o enfoque da atividade, obtendo-se como resultado "residual" o "verdadeiro" Vigotski, ainda é regularmente encontrado nas publicações contemporâneas.

A questão esbarra nos critérios segundo os quais julgamos se há ou não continuidade entre as duas espirais do pensamento teórico. Na história da ciência não são raros os casos em que pontos de vista teóricos, desenvolvidos

3. Vigodskaia G. L., Lifanova, T. M. Lev Semionovitch Vigotski: jizn, deiatelnost, chtnikhi k portretu [vida, atividade, traços para o retrato]. Moscou: Smisl, 1996. p.316-317 (N. dos AA.). 
Vigotski e Leontiev...

até mesmo por um único cientista em períodos diferentes da vida, são tão diversos que, sem saber que eles pertencem à mesma pessoa, pode-se notar entre eles total incompatibilidade. Ou, ao contrário: numa análise detalhada, pode-se encontrar algo em comum em dois autores de campos ideológicos e conceituais opostos. Em todo caso, nunca foi objeto de discussão o seguinte: ao introduzir muitas ideias novas, princípios e conceitos teóricos ao longo do processo de desenvolvimento de seus pontos de vista, ao alterar muitos pontos fortes, A. N. Leontiev não repeliu e nem contestou nada nos pontos de vista de seu mestre. As ideias de Vigotski poderiam ter sido desenvolvidas em outras direções, diferentes da teoria da atividade, porém ninguém conseguiu fazer isso em uma escala que pudesse, pelo menos, ser comparada com o enfoque da atividade. Por isso, questionar se foi de maneira "correta" que Leontiev assimilou e desenvolveu as ideias de Vigotski não faz sentido.

Todos os pingos nos "is" podem, portanto, agora, ser colocados graças à carta de Leontiev a Vigotski, encontrada nos arquivos de A. R. Luria, aqui transcrita na íntegra. A carta foi escrita antes da partida definitiva de Leontiev para Kharkov; sabia-se da sua existência, mas ela era considerada desaparecida. Por isso, é difícil expressar nossa gratidão à E. G. Radkovskaia ${ }^{4}$, herdeira e guardiã dos arquivos de A. R. Luria, que a entregou aos autores deste texto (a preparação dos originais para publicação foi realizada por A. A. Leontiev e D. A. Leontiev). Isso aconteceu 70 anos após a carta ter sido escrita, exatamente, em 5 de fevereiro de 2002, no dia do $29^{\circ}$ aniversário de Aleksei Nikolaievitch Leontiev.

Eis o pano de fundo histórico-científico da época. $\bigcirc$ final dos anos 20 e o início dos anos 30 foram marcados por uma guinada negativa na ciência, na cultura e na educação em geral. Os parafusos ideológicos começavam a ser "apertados". Nas ciências humanas isso se refletiu, particularmente, no surgimento de cientistas e de correntes científicas declarados como os unicamente marxistas (Marr, na linguística; Pokrovski, na história; Fritche, na crítica literária; Matsa, na crítica de arte). Os outros (incluindo os grandes linguistas Cherb e Polivanov, os excelentes críticos literários Eikhenbaum, Jirmunski e Chklovski e muitos outros) foram submetidos à crítica aniquiladora e, de tempos em tempos, a repressões. Na educação, teve fim a "escola única do trabalho",

4. Trata-se de Elena Luria (N. dos AA.). 
criada com os esforços de Krupskaia e Lunatcharski sob uma base conceitual elaborada por Blonski e Vigotski. Surgiu uma série de decretos do Comitê Central do Partido Comunista da Rússia (dos bolcheviques"****) - CC PCR(b) -, que retrocediam a escola soviética ao "ideal" do ginásio pré-revolucionário. Na psicologia ocorreu a discussão sobre a "teoria da reactologia", que resultou na destituição de K. N. Kornilov do cargo de diretor, em 1931. Foram veementemente destroçadas, do ponto de vista ideológico, a reflexologia e a psicotécnica de Bekhterev (todos os seus líderes em seguida sofreram repressão), o "behaviorismo" de Borovski e, finalmente, a escola histórico-cultural de Vigotski. Porém, a guinada principal foi feita na filosofia. Até 1930, a luta contra o materialismo vulgar era vencida pelo materialismo dialético, representado pelo chamado Grupo de Deborin, na direção dos estudos filosóficos na URSS (A. M. Deborin era diretor do Instituto de Filosofia). Mas, em dezembro de 1930, I. V. Stalin, em pessoa, discursou no núcleo partidário do Instituto do Professorado Vermelho e carimbou o Grupo de Deborin com a famosa etiqueta de "idealistas dos mencheviques". Um mês depois, foi publicado o decreto devastador do CC "Sobre a revista Sob a Bandeira do Marxismo". Chegaram ao poder os filosoficamente incompetentes e vulgarizadores diretos (que não tinham vergonha de tomar os argumentos dos materialistas mecânicos por eles mesmos severamente criticados), liderados pelos futuros catedráticos $M$. B. Mitin e P. F. ludin. O Grupo de Deborin foi aniquilado, uma parte fisicamente (B. N. Guessen, la. E. Sten), outra parte moralmente (o próprio A. M. Deborin). Vigotski era próximo do Grupo de Deborin por sua visão filosófica e, com frequência, referia-se a ele em suas publicações. E mais, no final dos anos $20 \mathrm{e}$ início dos 30, começaram a ser fechadas instituições científicas e de formação, às vezes, com escândalos políticos, onde trabalhavam tanto Vigotski quanto

\footnotetext{
*****Representantes de uma corrente política (facção), liderada por V. I. Lênin. O termo surgiu no $2^{\circ}$ Congresso do Partido Operário Social-Democrático da Rússia (1 903), quando, após a eleição para os órgãos principais do partido, foram eleitos pela "maioria" (bolchenstvo - maioria, em russo) os partidários de Lênin. Seus adversários obtiveram a "minoria" (menchenstvo - minoria, em russo) dos votos. De 1917 a 1952, a palavra bolchevique fazia parte da denominação oficial do partido, sendo Partido Operário Social-Democrático da Rússia (dos bolcheviques), ou Partido Comunista da Rússia (dos bolcheviques), entre outros. No $19^{\circ}$ Congresso, em 1952, passou-se a denominar Partido Comunista da União Soviética - PCUS. Fonte: Bolchoi entsiclopeditcheski slovar. Moskva, Sankt-Peterburg: Nautchnoie Izdatelstvo, Bolchoia Rossiskaia Entsiclopedia e Norint, 2000 (N. da T.).
} 
Vigotski e Leontiev...

Leontiev. Por exemplo, concomitantemente, surgiu uma nota de "porão", em dois principais jornais, sobre o Instituto Russo Estatal de Cinema, com o título ameaçador "O ninho dos idealistas e trotskistas". $\bigcirc$ esteio do grupo de Vigotski, a Academia de Educação Comunista, em 1930, caiu também em desgraça, e, em 1931, foi "deportada" para Leningrado e passou a ser denominada "Instituto". Ao mesmo tempo, Leontiev foi demitido da Academia em ${ }^{\circ}$ de setembro de 1931. Não havia condições nem de pensar em trabalhar no Instituto de Psicologia, apesar de as ideias de Vigotski e sua escola terem sido utilizadas nos programas do Instituto com a saída de Kornilov (esse assunto, particularmente, é abordado na carta de A. N. Leontiev). Ao livro de Leontiev Desenvolvimento da memória, publicado um ano antes, teve de ser anexada uma autocrítica ideológica em tom de retratação.

Vigotski, Luria e Leontiev, começaram a procurar local de trabalho onde pudessem dar continuidade ao ciclo de pesquisas iniciado. Tiveram sorte: os três receberam convite de Kharkov, naquela época, a ex-capital da República Socialista Soviética da Ucrânia, remetido pelo Comissariado de Proteção da Saúde (Narcomzdrav), S. I. Kantorovitch. O Narcomzdrav da Ucrânia resolveu criar, no Instituto de Psiconeurologia da Ucrânia (que mais tarde, em 1932, passou a ser a Academia Ucraniana de Psiconeurologia), o setor de psicologia ("setor psiconeurológico"). $\bigcirc$ cargo de diretor do instituto foi oferecido a Luria, o de diretor do Departamento de Psicologia Experimental (que mais tarde passou a se chamar Departamento de Psicologia Geral e Genética) foi oferecido a Leontiev. Oficialmente, Aleksei Nikolaievitch foi admitido no cargo, em I 5 de outubro de 1931. Em novembro de 1931, para o cargo de diretor da Cátedra de Psicologia Genética do Instituto Estatal de Formação de Quadros para o Narcomzdrav da Ucrânia foi admitido Vigotski ${ }^{5}$, porém, diferentemente de Luria e Leontiev, ele não se mudou para Kharkov, apesar de aparecer lá com frequência, fazendo palestras, dando aulas, fazendo provas como estudante do Instituto de Medicina (no qual ingressou no mesmo ano de 1931). Aliás, a mudança para Kharkov foi discutida várias vezes em sua família; falou-se até sobre a troca do apartamento em Moscou por um em Kharkov ${ }^{6}$. Porque a mudança não se realizou permaneceu um fato desconhecido. Segundo Luria, o

5 Vigodskaia, 1996, p. I28-129 (N. dos AA.).

6 Luria, 1982, p.73 (N. dos AA.). 
problema foi que Vigotski (e Luria) não conseguiram estabelecer boas relações com a direção da Academia de Psiconeurologia7. A. N. Leontiev relatou, no entanto, que a Vigotski foram oferecidas condições magníficas para a mudança e os motivos da recusa de Vigotski permaneceram incompreendidos.

Seja como for, em fevereiro de 1932, de uma forma ou de outra, os três ligaram as suas atividades a Kharkov e ficaram na estrada entre as duas cidades. No entanto, somente Leontiev resolveu mudar-se para Kharkov, transferindo para lá o centro de suas pesquisas. Provavelmente, tudo relacionava-se às diferentes situações de vida dos três. Vigotski estava com 35 anos, suas ideias já recebiam reconhecimento profissional. Vários livros de sua autoria foram publicados: Psicologia pedagógica, Pedologia do adolescente, Estudos sobre a história do comportamento (em coautoria com A. R. Luria). Vigotski sofria com a tuberculose e estava prevendo que lhe restava pouco tempo; então, além de todas as outras responsabilidades, trabalhou intensamente no livro Pensamento e linguagem. Leontiev, no dia em que escreveu a carta, tinha completado 29 anos. Os dois ou três últimos anos, passara mergulhado na teoria históricocultural de Vigotski. Seu livro Desenvolvimento da memória havia sido publicado recentemente. Nele, Leontiev apresentou o conhecido "paralelograma do desenvolvimento" - a lei de substituição da mediação externa das funções psíquicas pelo seu processo interno de desenvolvimento - o que representou a confirmação mais séria, por meio experimental, da teoria histórico-cultural. $\bigcirc$ ciclo de pesquisas estava terminado, o livro fora publicado; era preciso decidir o que fazer dali para frente.

Sobre o que aconteceu posteriormente, a carta, escrita antes da partida para Kharkov, fala por si.

Ela representa não só um documento histórico ímpar, mas também existencial. Até mesmo o leitor distante da psicologia, que nada conhece dos percalços de sua história em nosso país e que queira pular as partes incompreensíveis, ficaria impressionado com o relato de um homem forte e singular que, num momento difícil de escolha, tomou decisões a respeito não só de sua vida pessoal, mas de todo o trabalho que era o sentido de sua vida. A escolha foi feita conscientemente e com total responsabilidade, levando em consideração condições completamente imprevisíveis. A sorte estava lançada;

$7 \operatorname{Idem}(N \cdot \operatorname{dos} A A$.$) .$ 
Vigotski e Leontiev..

o Rubicão, vencido - esse é o sentido da carta. Pelos menos três níveis podem ser nela destacados: o nível da personalidade, no momento de uma escolha existencial, o das relações interpessoais e o nível do desenvolvimento das ideias. E é assim que a carta deve ser lida.

Leontiev começa a carta, dizendo que a escolha fora feita: a passagem estava comprada e o telegrama enviado. No dia seguinte, ele estaria cortando o nó que teimava em não se desfazer. A carta foi escrita com uma letra firme e com abundantes destaques, o que era característico de Leontiev. Ele não apenas sublinhava as palavras que considerava importantes, mas as destacava, passando várias vezes a caneta por cima delas (assim como nas publicações são destacadas as palavras em negrito). Percebe-se que a carta não foi redigida de forma impulsiva, foi bem pensada e sofrida. Leontiev constata: nosso trabalho comum está em crise. Vigotski, como evidencia a carta, não queria travar a conversa. Leontiev não se apressa em reprová-lo: no final da carta, admite a possibilidade de que Vigotski estivesse certo, antecipando com isso um determinado desfecho da situação. Aceita isso como um fato que deve levar em conta ao tomar sua decisão. Uma das características peculiares desse documento é a nítida diferenciação que Leontiev faz entre o que pode fazer sozinho e o que não depende dele, o desejado e o real. Ele entende a implacável lógica da vida e, ao entrar na luta por seus valores e seu trabalho, prepara-se para o pior. Leontiev fala da possibilidade de ter que deixar a psicologia, evidentemente sem desejar isso, assim como sobre o inevitável, mas não desejado rompimento com A. R. Luria (constata-se pela carta, a dor que the provoca esse assunto), a quem reprova por uma série de erros, embora o tom seja de amizade. Sabemos que, felizmente, nada disso aconteceu: Leontiev não teve que deixar a psicologia e sua relação de profunda amizade com Aleksandr Romanovitch Luria passou pelo teste de resistência.

Leontiev toma a si a responsabilidade por tudo e o texto da carta deixa transparecer o peso em suas costas. A preocupação era que, à medida que as ideias da psicologia cultural ou instrumental (como ela se chamava antes) de Vigotski eram divulgadas, essa psicologia era corroída. O próprio Vigotski não se opunha a isso e Luria, que gostava e tinha inclinações para coisas ecléticas, até colaborava. Leontiev não se contrapunha a Vigotski e não há na carta uma palavra sequer que indique que tivesse qualquer outra alternativa; ao contrário, ele se refere a cartas que Vigotski lhe escrevera, três anos antes, reprovando-se 
pelo distanciamento dos próprios princípios. Leontiev com Vigotski de 1929; Leontiev contra Vigotski de 1932. Leontiev revela-se na carta um grande partidário de Vigotski, enquanto o próprio Vigotski, plus royale que le roi ${ }^{8}$, acusa a si mesmo de incoerência. Ao contrário, Leontiev desconfia que Vigotski havia amadurecido a decisão de se separar. O "nós" soa na carta, desde as primeiras linhas até o final, unindo, além de Vigotski, Leontiev e Luria, também o núcleo do futuro Grupo de Kharkov; são lembrados A. V. Zaporojets, L. I. Bojovitch e N. G. Morozova. Leontiev refere-se a todos com carinho ("um grupo maravilhoso, fiel e que resistiu à prova de precisão e firmeza"), porém com um sentimento de responsabilidade madura ("Eles nos incumbem. É impossível que não passem na prova!"). Ele chama Vigotski, sublinha várias vezes que não apresenta nenhuma reclamação, diz que não sabe como trabalhar sozinho, sem Vigotski, mas sente que está tomando a decisão certa do ponto de vista estritamente pessoal, ou seja, dos sentidos e dos valores que unem os três. As relações pessoais, continua Leontiev, referindo-se novamente à carta de Vigotski de três anos antes, são secundárias, elas seriam resolvidas com a resolução do problema principal, o problema das ideias.

As reflexões teóricas e metodológicas de Leontiev sobre a psicologia cultural formam um bloco separado e interessante na carta. Boa parte delas se ocupam das bases da teoria filosófico-metodológica que eram características de Leontiev. Dos inúmeros problemas concretos, antes de mais nada, aparece o problema do psíquico e do psicológico, que alguns anos mais tarde se transformaria no objeto de sua tese de doutorado. O problema dos sistemas funcionais e das ligações interfuncionais tornou-se central para toda a escola entre os anos 40 e 60. Assim como o papel-chave do sinal. E, finalmente, o problema da vontade e da intenção e, no contexto do problema do desenvolvimento, o da personalidade como de seu sujeito, ou seja, "o problema do desenvolvimento psicológico ativo, o problema da cultura psicológica da personalidade (liberdade!) e, a partir disso, os problemas éticos mais imediatos". Essa apresentação da questão soa nova ainda hoje. Mas esses problemas logo entraram no país para a "lista negra" e é somente em cadernetas de anotação e em frases separadas, que irromperam nas publicações dos seus últimos anos de vida, que encontramos o problema que preocupava Leontiev: a personali-

8. "Mais realista do que o rei" (fr.) (N.dos AA.). 
Vigotski e Leontiev...

dade não como objeto das influências formativas, mas como um sujeito ativo e responsável pelo próprio desenvolvimento, a personalidade com a qual ele mesmo se revela nessa carta.

A carta termina no nível existencial. $\bigcirc$ medo diante do futuro, a sentnça, a condenação à solidão, o sentimento de uma nova prova pela qual deveria passar em Kharkov. E o sentimento de alívio nas últimas linhas; apesar do peso, estava feliz por tê-la escrito e livre porque fez o que deveria ter sido feito. Isso porque o destino da psicologia cultural estava acima de tudo.

\section{CARTA DE LEONTIEV A VIGOTSKI}

5.2 .32

Moscou

Querido Lev Semionovitch,

Amanhã, parto para Kh[arko]v*****; comprei a passagem, passei o telegrama; amanhã é o prazo final para a minha "autodeterminação" na complexa e sofrida situação que se configurou aqui e lá.

Uma enorme quantidade de questões de importância vital e de complexidade incomensurável deve ser resolvida amanhã. Está claro para mim que, se os nós não se desfazem, então, em situações extremas, devem ser cortados. Agora é exatamente essa situação extrema. Por isso eu vou cortá-los.

Os fatos são teimosos; isso significa que não se deve resistir a eles; pareceme que devem ser aceitos com mais coragem e mais clareza. Hoje, o fato central para mim é o fato da minha solidão de fato. Nossa grande conversa não aconteceu e eu não posso aceitar isso como um fato "mudo"; ele diz muito e demais. Não quero e não posso adivinhar e construir suposições; não vou tentar decodificá-lo. Somente o considero.

Isso significa que sou obrigado a agir assim, como se essa conversa fosse totalmente impossível. A primeira conclusão e o primeiro passo é a carta. Antes de mais nada, eu quero "me determinar" (desculpe pela palavra tola, não há

***** No original em russo, várias palavras são abreviadas, indicando-se apenas as letras iniciais e finais. Na transcrição desta carta, por ocasião da publicação, os autores deste artigo documental colocaram entre colchetes as letras faltantes das palavras, para facilitar a leitura (N. da T.). 
tempo para refletir sobre as expressões!) em relação a você, encerrar a conversa iniciada por mim, por um monólogo. Que seja um monólogo, ou seja, palavras que não obrigam a responder.

Você mesmo entende que, agora, nós, como um grupo de pessoas ligadas por ideias, estamos passando por uma enorme crise. Crises como essas, conflitos internos como esses, não são resolvidos de maneira simples e sem sofrimento. Com mais frequência são resolvidas com um tiro.

As circunstâncias externas, a enorme pressão delas sobre todos nós, a situação ininterrupta "I 02-104" [?], os baldes de água fria por toda parte, as tesouras entre o movimento do pensamento e o lado do trabalho organizado externamente, o atraso do trabalho concreto e, com isso, a expansão (o erro de alguns de nós = A. R. [Luria]!) de ideias, tudo isso amarrotou, implodiu e destruiu o nosso trabalho comum. $O$ próprio sistema de ideias está em enorme perigo (agora, diante de mim está um documento - o programa padrão de psicologia que está sendo desenvolvido para toda a URSS pelo grupo composto por Ved[ionov], Chvarts, Akimov, $\underline{\text { Sapir }}^{9}$ etc., pelo projeto de A.R. [Luria]. O I[nstitu]to ${ }^{10}$ trabalha seguindo nossos planejamentos. Isso é alienação das nossas ideias. É início da queda total, da perda de substância do sistema.

Por isso, considero meu dever gritar sobre isso, fazer alarde. Eu apresentei essa questão a você não por acaso; durante um longo tempo fiquei em dúvida. Penso eu que fiz o certo; eis o que você me escreveu há dois anos (eu guardei suas cartas tão valiosas e, agora, num momento decisivo, as reli):

"Então, estabelecer um severo regime monástico de pensamento; isolamento de ideias, caso seja necessário. $\bigcirc$ mesmo deve ser exigido dos outros. Explicar que trabalhar com a psicologia cultural não é brincadeira, nem nos intervalos do trabalho ou mesmo ao longo de uma série de outros trabalhos; também não é terreno para as dúvidas próprias de cada nova pessoa. Externamente, disso decorre o mesmo regime organizacional... Confio firmemente na sua iniciativa e no papel de preservação disso" (1929).

Eu não me esqueci desta última frase e, por isso, faço alarde.

9. A. V. Vedionov, L. M. Chvarts, I. D. Sapir - funcionários do Instituto de Psicologia, Pedologia e Psicotécnica, em 1930 (N. dos AA.).

10. Instituto Psicológico, que se denominava, em 1932, Instituto de Psicologia, Pedologia e Psicotécnica (N. dos AA.). 
Vigotski e Leontiev...

Não estou histérico e nem penso que devemos nos separar e que você deve permanecer sem nós, sozinho (a sua p[ode] s[er] uma decisão espontânea, não é?). É preciso caminhar em frente com a luta! É preciso.

Temos um grupo maravilhoso, fiel e que, nesse momento, resistiu à prova de precisão e de resistência, que é composto de três ou quatro pessoas provavelmente (A. V. [Zaporojets], L. I. [Bojovitch], N. G. [Morozova]..., pode haver outros. Eles nos incumbem.). Não é possível que não passemos no teste!

Onde estão os caminhos, como seguir em frente, por qual caminho seguir? A isso eu só posso responder com as palavras do Brand, de Ibsen:

- "Para outros, direto ao alvo!..

Quanto mais tortuoso o caminho,

Mais direto, mais curto." "।

Eu o chamo; isso não pode parecer-lhe absurdo: eu o chamo! Essa é a última coisa que posso fazer no âmbito do nosso trabalho comum. Decida: estou pronto para receber sua recusa, mesmo que os nossos caminhos se separem, os caminhos externos, pois eu não creio na possibilidade de divergências de ideias. Quero que entenda: não estou apresentando qualquer reclamação, não o obrigo a nada, nada peço: estou dizendo somente aquilo que me considero obrigado a dizer; antes de mais nada, obrigado diante de mim mesmo!

Sem você vou tentar encontrar o meu caminho, pode ser que esteja fora da psicologia... Pois posso não ter forças suficientes para trabalhar só, sem você, como é preciso. E não quero compensar com invencionices e biscates. Pode ser que eu consiga encontrar um meio de empregar as minhas principais qualidades: força de decisão, coragem, firmeza... É a última coisa que eu posso entregar a esse "nosso". Como? Não sei.

"Há vantagem - você me escreveu - que a $\underline{P}$ [sicologia] I[nstrumental] tenha caído no rol das atividades desvantajosas. Particularmente, não posso expressar com força suficiente como ponho no alto (no campo ético) a ideia sobre a máxima pureza e o rigor da ideia. Essa é a nossa tarefa principal contra a confusão e o "habitué".

Como eu desejo agora que isso não fosse assim!

I I. H. Ibsen. Brand. (N. dos AA.). 
O destino do grande lapidário ${ }^{12}$ é sua grandeza multiplicada pela consciência não da solidão, mas pela consciência do apoio, da compreensão que seja de 2 ou 3 pessoas, mas pessoas vivas! Aquilo que transforma a quimera em realidade! - Lembra-se dessa ideia?

Sobre as nossas relações pessoais. Aqui também não posso deixar de citar você - aceite essa última (prometo!) citação:

"Em uma coisa eu o apoio até o fim e vejo nisso a salvação: maximum ${ }^{13} \mathrm{de}$ precisão organizacional e firmeza de caráter - isso é a pedra angular da pureza interna da pesquisa, e é a suprema lex ${ }^{14}$ também da PUREZA DAS RELAÇÕES PESSOAIS."

Pois bem: as relações pessoais se resolvem ao resolvermos o problema principal. São restabelecidas automaticamente com o restabelecimento das relações de ideias. É um pensamento correto. Também entendi-o realmente.

Agora as duas últimas questões: minha relação com A.R. [Luria] e a minha relação com o trabalho.

Brevemente sobre a primeira:

Ao preço de qualquer sofrimento, de qualquer crueldade, devem-se colocar as cartas na mesa. Abro as minhas:

J'accuse ${ }^{15}$.

Somente o principal - I) o não entendimento do caminho, da perspectiva, não entendimento daquilo que a P[sicologia] C[ultural] - um sistema também filosófico, ou seja, ela não pode ser adaptável àquele ou outro dogma fil[osófico]. Sua filosofia não é acrescentada a ele mecanicamente! Disso surge um amontoado de erros: "amigos" da dir[eção?], tentativas de reconciliar o "externo" e o "interno", o ecletismo, a utilização formal dos conceitos da P[sicologia] C[ultural] ("abrem" os cadeados dos problemas não do conceito in abstr[acto] ${ }^{16}$, mas da pesquisa no sistema de conceitos dados!), um tipo de ideia como "Uma semen-

12. Pelo visto, Leontiev está se referindo à B. Espinosa, que tinha a lapidação de vidros como sua profissão principal; seu destino e suas ideias serviram de exemplo para L. S. Vigotski; veja a carta de Vigotski mais adiante (N. dos AA.).

13. Lat. (N. dos AA.).

14. Lei suprema (lat.) (N. dos AA.).

15. "Eu acuso" (fr.), título do famoso panfleto de E. Zola, escrito por ocasião do famoso processo de Dreyfus (N. dos AA.)

16. Lat. (N. dos AA.). 
Vigotski e Leontiev..

te sã da P[sicologia] C[ultural] é a sociogênese; o resto vem da "manivela" da inteligentsia etc.

2) Provavelmente a relação com os sistemas idealist[as]

3) A postura empresarial, provavelmente com relação à piatiorka*****, que quase a destruiu (mas não a destruiu!), não desgastou as raras e preciosas relações pessoais de seus membros.

4) A relação equivocada com a própria $\mathrm{P}[$ sicologia $] \mathrm{C}[$ ultural]. $\bigcirc \underline{\text { menosprezo }}$ por ela (por mais paradoxal que isso possa soar!), ou seja, provavelmente, a super valorização, mas utilitarista, especulativa, falando grosso modo.

Tudo isso eu estou dizendo de forma terrivelmente primitiva e terrivelmente brusca, mas não há tempo para desenvolver e não quero escamotear; é melhor pender para esse lado. Você, é claro, fará com a sua mão as correções, fará as complementações e entenderá corretamente.

Por último: o que eu particularmente penso da P[sicologia] C[ultural].

Serei também terrivelmente sucinto:

I. É impossível a exploração dos postulados da P[sicologia] C[ultural] (o emprego delas em tarefas concr[etas]), no momento, pois isso extrapola a tarefa principal de continuar a elaboração dos próprias postulados. Ela destrói a lógica da pesquisa e acarreta um estreitamento de seus principais conceitos.

2. A lógica do desenvolvimento do sistema da P[sicologia] C[ultural], hoje, leva à necessidade de colocar no centro de sua atenção a tarefa de compreensão filosófica de seus conceitos e postulados básicos (a divergência entre o conteúdo de fato das pesquisas e o grau de elaboração de suas bases filosófic[as], da visão de mundo que está em seus fundamentos. "Pictórico").

3. Essa tarefa (mais uma vez sobre isso nesse plano!) não pode ser resolvida a custo da adaptação da P[sicologia] C[ultural] ao "padrão"; dizendo de outra forma, ela não pode ser introduzida mecanicamente naquele ou em outro contexto filos[ófico]. Ela mesma é um sistema filosófico (filosofia psicológica! - uma visão de mundo!)

4. Agora, é necessário apresentar claramente as questões "de controle" e, ao mesmo tempo, de princípios, do tipo: local do trabalho (liquidar a torpeza

\footnotetext{
${ }^{* * * * * * * *}$ Em russo, um grupo, ou conjunto, de cinco pessoas ou objetos ( $N$.da T.).
} 
do "trabalhismo 17; consequentemente, o problema da mediação do desenvolvimento (eu penso: o desenvolvimento cultural!); o problema das leis específicas, próprias, imanentes ao desenvolvimento psicológ[ico]. Pode até ser - o conceito de psíquico e psicológico, os caminhos principais para o estudo do psíquico, ou seja, como isso seria possível em princípios (pode ser que a física aqui sirva de farol!). O principal: a personalidade, como sujeito do desenvolvimento ps[icológico], ou seja, o problema do desenvolvimento psicológico ativo, o problema da cultura psic[ológica] da personalidade (liberdade!) e daí os problemas éticos iminentes.

5. Além dessas questões, é necessário resolver, elaborar questões teóricas que conduzam diretamente a pesquisas concretas. Parece-me que estão incluídas aí: a) O problema dos S[istemas] F[uncionais]: I ) "possíveis" (ou seja, como se fossem quânticos) ligações i[ntra]f[uncionais] e "possíveis" funções das funções (pois o sist[ema] não é uma salada "primavera", mas algo que pressupõe somente combinações possíveis, ou seja, determinadas). b) A determinação das ligações i[ntra]f[uncionais] (condições nas quais elas surgem, o processo de seu nascimento, os fatores (= determinantes); - aqui, o experimento é necessário em função da construção artificial deles, ou seja, é necessário "um argumento dinâmico", experimento do tipo "enraizamento"). Aqui, é necessário pensar no local, no papel do sinal; minha convicção, ou melhor, intuição, é de que a chave está no sinal! Aproximadamente no esquema: as primeiras operações com quantidades estão na percepção; em seguida, o s[istema] f[uncional] da percepção, a operação intel[ectual]. $\bigcirc$ que transformou a percep[ção] das quantidades, essa operação simples, numa função int[electual] superior? A introdução de um sinal original, de um conceito de número, ou seja, de um sinal, de um recurso do intel[ecto] (pensamento!). Se esse conceito é válido, então, a percepção, as operações com as quantidades são introduzidas por ele no sist[ema] do pensamento conceitual. Isso tudo de forma muito rudimentar e o exemplo não é dos melhores (parece que não há tempo para pensar!). c) O problema "intelecto-vontade", ou seja, o problema (a decifração do problema!) da intenção (isso já está dado!), e d) Personalidade como sist[ema] em problemas concr[etos], ou seja, como se forma.

17. Pelo visto, deve estar considerando a teoria e a prática da instrução e educação pelo trabalho, que se fortalecia na pedagogia soviética (N. dos AA.). 
Vigotski e Leontiev..

6. Essas questões teóricas não coincidem com os principais problemas gerais (não se identificam), apesar de não serem neutras umas em relação às outras. Elas estão ligadas em um sistema, isto é, organicamente, mas (o mais importante!) não passam de uma para a outra de forma "projetiva" (geometria projetiva).

A relação desses problemas teóricos com a pesquisa é exatamente projetiva (ou seja, a relação da passagem de uns para outros pela transformação projetiva, pela projeção sobre diferentes superfícies dos mesmos dados).

Isso eu também não expressei de forma muito clara; a ideia principal aqui é não diluir uma coisa em outra. É necessário: destacar os problemas filosóficos; como tais eles não se resolvem experimentalmente; a pesquisa dá-lhes somente uma verificação indireta e uma elaboração. Seguindo: os postulados teór [icos] concretos, reguladores, as principais pesquisas concr[etas] devem projetar-se diretamente na pesq[uisa]. Aqui, é a confluência, mas quanto maior (ela é necessária!), mais precisa deve ser sua desmembração na formulação do problema. Ou seja, em qualquer pesquisa deve estar claro qual o problema teórico que ela está resolvendo, sua contribuição à P[sicologia] C[ultural].

Parece-me que isso é o mais importante sobre a última questão.

Estou escrevendo tudo isso para que fique o mais claro possível para você (o volume da carta me limita!) a minha relação com o principal.

Então, eu volto a mim mesmo.

É terrível pensar no futuro. O sentimento de solidão é um grande peso. A nossa conversa que não aconteceu, a sua não-participação (pode ser que você esteja certo!), é a sentença, uma decisão expressa sem palavras. Cada vez mais parece que será preciso ir embora da ps[icologia]. Em dupla com AR[Luria] é impossível para mim. Não conseguirei sozinho (faltará preparo, escola etc.), se pelo menos não encontrar uma saída exclusiva. Até a primavera será a sofrida permanência em Kh[arko]v. Sofrida porque (você deve entender isso!) estender assim, como ocorreu nos últimos tempos (internamente, ideologicamente), eu decididamente não posso mais.

Será que você está certo, será que agora a salvação está na sua solidão (no sentido de liquidação do nosso trabalho comum, como comum)?

Eu lembro o seu orgulhoso "hier stehe ich"18, então, não é por acaso que isso significa aquilo no que é difícil de acreditar - a necessidade?

18. "Aqui me detenho" (alem.), conhecido aforismo de Martinho Lutero (N. dos AA.) 
Com você ainda me parecia que seria possível endireitar tudo, acertar com $A R$, levantar o ânimo, cortando algo, liquidando algo com dor (possivelmente o rompimento com AR, como é difícil escrever isso!), encontrar novas possibilidades. Em resumo: passar no teste.

A última dificuldade: todos nós iremos nos encontrar (provavelmente) no trabalho. Será como antes, mas de forma nova? Então, significa que é preciso reconstruir tudo com Leb[edinski] ${ }^{19}$ pois a minha demissão do trabalho aqui estava encoberta (a precisão, a delimitação fariam isso, tenho quase certeza).

Pois bem, o meu monólogo inesperadamente longo (em minha defesa posso me referir somente ao conhecido "não havia tempo para escrever com brevidade") está chegando ao fim. Falando sem rodeios, estou feliz por ter escrito essa carta. Eu fiz tudo que podia ter feito aqui. Não peço que me responda. Eu sou livre, num certo sentido; fiz tudo o que podia, esclareci-me completamente a você. Espero que consiga o mesmo com A[leksandr] R[omanovitch].

Não preciso dizer isso a você, mas, de tudo, o que menos pode permanecer em mim é qualquer que seja a parcela de queixa em relação a você.

Seu A. Leontiev

Não sabemos se Vigotski respondeu a Leontiev naquele momento. Aliás, Leontiev não pediu resposta. Mas, nos seus arquivos conservou-se uma carta de Vigotski a ele endereçada, com data de 7 de agosto de 1933. Essa carta merece ser transcrita na íntegra.

\section{CARTA DE VIGOTSKI A LEONTIEV}

Querido Aleksei Nikolaievitch,

Durante algum tempo, pensei em enviar a carta por A[leksandr] R[omanovitch], mas antes da partida dele nós não nos encontramos, por isso o atraso. Sinto, e não é a primeira vez, que estamos diante de uma conversa importante para a qual ainda, pelo visto, nós dois não estamos preparados e, por isso, não temos uma ideia boa de como ela deve acontecer. Porém, a conversa já teve alguns

19. M. S. Lebedinski, psiquiatra, trabalhou durante algum tempo com A. R. Luria; foi convidado para Kharkov junto com Vigotski, Leontiev e Luria e trabalhou lá por alguns anos (N. dos AA.). 
Vigotski e Leontiev...

lampejos, inclusive na sua última carta, por isso, não posso deixar de responder com o mesmo lampejo, com algo parecido com intuições (nebulosas) de uma conversa futura.

O seu destino externo resolve-se, pelo visto, no outono e por alguns anos e, ao mesmo tempo, o nosso destino (o meu também), parcialmente, assim como o destino do nosso trabalho. Por mais subjetivamente que você vivencie o "exílio" em Kharkov, por mais que este seja compensado com alegrias (do passado e mais ainda do futuro), a sua partida definitiva, objetivamente, pelo seu sentido interno, é nosso fracasso interno pesado e, p[ode] s[er], incorrigível, que decorre dos nossos equívocos e negligências diretas em relação ao trabalho que nos foi delegado. Pelo visto, pela segunda vez, nem na sua biografia, nem na minha, se repetirá aquilo que uma vez aconteceu também na história da nossa psicologia. Pois bem, tento receber isso tudo à Espinosa, com pesar, mas como necessário. Nos pensamentos comigo mesmo parto disso como um fato já consumado.

O destino interno não pode deixar de resolver-se fora da relação com o externo, mas, é claro, não se determina completamente por ele. Por isso, ele não está claro para mim, é nebuloso, vejo-o embaçado e isso me inquieta com o maior dos desassossegos que já vivenciei nos últimos tempos.

Mas, uma vez que a sua posição interna, como você escreve, no plano pessoal e científico, cristalizou-se, então, a decisão externa, em certo grau, também está definida. Você tem razão de ter que se livrar, antes de tudo, da necessidade de se comportar de forma dupla. Poderia fazer isso com ajuda da "abstração" (de maneira kharkoviana) ou da desagregação (de maneira moscovita), independentemente das condições externas de qualquer um de nós. Então, considero isso correto, apesar de avaliar de forma diferente tudo o que aconteceu com A[leksandr] R[omanovitch] (num plano mal-sucedido). Mas sobre isso, num momento oportuno.

Sei e considero correto que, internamente, em dois anos, você fez um caminho (definitivo) rumo à maturidade. Desejo a você do fundo da minha alma, assim como desejaria felicidade, num instante decisivo, à pessoa mais próxima, forças, coragem e clareza de espírito diante da decisão da sua linha de vida. $\bigcirc$ principal: decida livremente.

Sua carta finda nesse ponto, então, nesse ponto eu também findarei a minha, é certo que sem um motivo externo.

Aperto forte-forte a sua mão.

De toda alma, seu L. Vigotski. 
P.S. Não sei se irei a Tarusa. Farei isso somente em caso de a conversa amadurecer e se eu resolver pôr um ponto final nela.

Senão, para que ir? Lembranças à M[argarita] P[etrovna] e A[leksandr] R[omanovitch] e sua mulher.

O conteúdo da carta de Vigotski nos leva a pensar que ela é a resposta à carta de Leontiev, aqui transcrita. Isso, em parte, é contradito pelo enorme intervalo de tempo entre as duas correspondências; não se pode eliminar a possibilidade de equívoco da data da carta de Leontiev (ou seja, que ela é não de fevereiro de 1932, mas de 1933, o que é quase improvável), ou da carta de Vigotski (que, então, seria de 1932, o que é bem mais provável).

Há um cartão escrito por Vigotski que foi milagrosamente conservado e que pode ser da primavera de 1934. A data está ilegível. No texto se pode ler: "Por enquanto, gostaria de me movimentar naquela direção que combinamos com você, levando com firmeza a linha interna para a total convergência de nossos estudos". É muito provável que esse cartão tenha sido escrito na primavera de 1934, porque nele Vigotski indaga pessoalmente a Leontiev sobre o destino das teses para um congresso (tem-se em vista o Primeiro Congresso de Psiconeurologia da Ucrânia, de junho de 1934, para o qual Lev Semionovitch enviou o trabalho "A psicologia e o estudo da localização das funções psíquicas").

Conservou-se uma carta de Margarita Petrovna a Aleksei Nikolaievitch, de 23 de março de 1934. Por ela percebe-se que Vigotski pretendia convidar Aleksei Nikolaievitch para o seu departamento: Margarita Petrovna fala sobre uma conversa telefônica entre Luria e Leontiev, em que Luria teria comunicado a este que "hoje ficará tudo esclarecido com a base do Instituto de Medicina Experimental da Rússia (IMER), e o segundo ponto de pauta é você. Vigotski disse a eles que precisaria de você agora, mas já que não deu, tem de pegar você por outras portas". De fato, no dia 13 de abril de 1934, a direção do IMER enviou para o Instituto da Ucrânia de Pedagogia Científica um pedido de não oposição à transferência de Aleksei Nikolaievitch para o trabalho no IMER. O pedido começava assim: "Por ocasião do convite ao prof. A. N. Leontiev para trabalhar no Departamento Psicológico da filial de Moscou do IMER, na qualidade de substituto do diretor do Departamento...".

Depois da partida de Aleksei Nikolaievitch, aconteceu o seguinte. 
Vigotski e Leontiev..

Durante três anos, até 1934, Luria ia a Kharkov de vez em quando; segundo suas próprias recordações, "viajava" entre Kharkov e Moscou (e Vigotski entre Kharkov, Leningrado e Moscou). Por pouco tempo, L. I. Bojovitch esteve em Kharkov. Logo ela transferiu-se para o Instituto de Pedagogia, em Poltava, apesar de continuar a colaborar com o grupo de Kharkov. De vez em quando Vigotski visitava-a.

Leontiev permaneceu em Kharkov durante quase cinco anos. Ele não apenas dirigia o Departamento e era membro efetivo da Academia de Psiconeurologia da Ucrânia, mas, após a partida definitiva de Luria, recebeu dele a direção de todo o Setor de Psicologia (em 1932, ele fora substituto do diretor do setor). Além disso, era o Diretor da Cátedra de Psicologia do Instituto Médico-Pedagógico do Comissariado de Saúde da Ucrânia e, mais tarde, Diretor da Cátedra de Psicologia do Instituto de Pedagogia de Kharkov e do Instituto Científico de Pesquisa Pedagógica (mais tarde renomeado como Instituto de Pedagogia Científica da Ucrânia).

Dessa forma, das cartas transcritas de A. N. Leontiev e L. S. Vigotski, assim como dos acontecimentos que se desenvolveram posteriormente, fica claro que a partida de Leontiev para Kharkov não foi um rompimento com Vigotski. Em primeiro lugar, Leontiev partiu, exatamente, para ocupar-se de desdobramentos da psicologia cultural, o que era difícil de fazer em Moscou. Em segundo lugar, Vigotski e Luria também receberam convites de Kharkov e, concomitantemente a Leontiev, lá começaram a trabalhar, apesar de não ter sido de maneira tão definitiva. A Leontiev não se pode "culpar" por ter sido exatamente quem se revelou na posição de único líder real do Grupo de Kharkov e que lá, com a sua ajuda, tenha-se formado um coletivo forte de correligionários que se armou com as ideias da psicologia histórico-cultural, ao passo que, em Moscou, esse coletivo não se organizou. Em terceiro lugar, tendo como pano de fundo a crise de ideias, o próprio Vigotski distanciou-se do contato mais aprofundado, o que levou Leontiev à tomada de decisões autônomas, mas que, de forma alguma, acarretaram mudança nos pontos de vista científicos e nas relações pessoais. Em quarto, a partida de Leontiev não era uma cisão teórica; não há uma menção sequer a isso nas cartas; ações mais tardias de Vigotski comprovam-no sem ambiguidade e, ao mesmo tempo, negam o mito da "traição" e das "relações não restabelecidas". 


\section{ENTREVISTA COM DMITRI ALEKSEEVITCH LEONTIEV}

Concedida às autoras em 8 de novembro de 2007, em Moscou

Eram, aproximadamente, 15 horas. Fazia bastante frio. Caminhávamos da estação do metrô até o Instituto de Psicologia da Universidade de Moscou para o encontro com o Professor Dmitri Alekseevitch Leontiev. Havíamos nos preparado para essa visita, mas, mesmo assim, ao entrarmos no hall do Instituto de Psicologia, pudemos perceber o quanto estávamos ansiosas. Apresentamo-nos rapidamente: Elizabeth Tunes, Professora do Programa de Pós-Graduação em Educação da Universidade de Brasília, Zoia Prestes, a tradutora e intérprete do grupo, Patrícia Pederiva, Tereza Mudado e Elisângela Peraci, da Universidade de Brasília.

O Professor Dmitri - um homem de meia idade, mostrou-se muito simpático, gentil e atencioso. Ele sabia dos motivos da visita, pois já havíamos trocado correspondência. Assim, tratamos de diversos assuntos ligados à psicologia soviética e ao trabalho dele na atualidade. Apresentamos, aqui, apenas uma síntese da entrevista em que foi abordada a questão do suposto rompimento de seu avô com L. S. Vigotski.

Seu primeiro gesto foi presentear-nos com a biografia de seu avô, escrita por ele, seu pai e a Professora Sokolova. Em seguida, referiu-se ao episódio em que Elena, filha adotiva de Luria, entregou-Ihe e a seu pai a carta tida como desaparecida. Surpresos, eles reconheceram a autoria de A. N. Leontiev pela letra, estilo e lógica textual. Diante do fato de alguns autores (como por exemplo, Blanck, 2003) questionarem a lenda da "troika" (Vigotski, Leontiev e Luria), perguntamos-Ihe o que pensava a respeito. Respondeu-nos, fazendo uma advertência: "a 'troika' existiu, assim como existiu a 'piatiorka'. Deve-se, simplesmente, ler os originais com seriedade e atenção".

Também pedimos-Ihe que opinasse sobre a ideia de ser a teoria da atividade de A. N. Leontiev uma continuidade das concepções teóricas de Vigotski, uma vez que há controvérsias sobre essa questão. Eis o que disse:

Já escrevi bastante sobre isso. Eles não pensaram juntos essa teoria, visto que as primeiras e principais concepções da teoria da atividade foram formuladas cinco anos depois da morte de Vigotski. Mas, eu diria o seguinte: a teoria da atividade 
Vigotski e Leontiev...

representa um certo modo de desdobramento da teoria de Vigotski. As ideias deste estudioso podem ser desdobradas e a teoria da atividade não tem qualquer contradição com elas. Ela não é o único modo possível de desdobramento de tais ideias, que podem ser desenvolvidas em outras direções. Todavia, isso não aconteceu. Não era a única possibilidade, mas foi a única que se concretizou em tal escala. É uma parte do projeto de Vigotski. Vigotski já falava de atividade.

Muito do que se fala sobre a relação entre as concepções de Vigotski e de Leontiev é subjetivo e carece de critérios objetivos de comparação. Para se examinar a continuidade de uma teoria em relação a outra faz-se necessário ter critérios objetivos. Quando comparamos os pontos de vista de um mesmo autor, no início do seu trabalho científico e em tempos posteriores, não é raro termos a impressão de se tratarem de teorias completamente diferentes. Ou seja, até uma mesma pessoa pode mudar de direção. Porém, existem dois fatos importantes. $O$ primeiro é que entre a teoria da atividade e aquilo que foi formulado pelo próprio Vigotski não há contradições e o segundo é que não foi concretizada nenhuma outra versão, mas somente a teoria da atividade.

É um erro identificar a teoria da atividade apenas com os trabalhos de A. N. Leontiev porque a escola da psicologia da atividade é uma das poucas que continuaram a se desenvolver depois da morte do seu fundador, sem deixar cair o nível. Escolas como essas são raras. Na psicologia da atividade muito se fez após a morte de Aleksei Nikolaievitch. É uma teoria aberta, mas uma teoria de fato. São poucas escolas assim no mundo.

Então, há uma grande escola. Quando sairmos daqui e passarmos no instituto, vou mostrar-lhes muitos livros interessantes que reúnem vários trabalhos. O último livro saiu recentemente, mas foi organizado por meu pai, depois da grande conferência, que ocorreu em 2003, em homenagem aos 100 anos de A. N. Leontiev. Principal organizador dessa conferência, meu pai reuniu o material do evento em forma de uma monografia coletiva que, durante algum tempo, não foi possível editar. Nesse livro não estão representados 100\% dos que seguem a teoria da atividade. Há ainda outro livro, que saiu um pouco antes.

Mas, existe um porém: o mundo psicológico mudou a partir dos anos 70 . Antes dessa época, a psicologia estava dividida em escolas concorrentes. Cada escola agrupava-se em torno de um líder, que era a autoridade absoluta. Cada psicólogo devia pertencer a alguma escola. Era assim aqui e no ocidente. A partir dos anos 70, esse quadro começou a mudar no mundo inteiro, aqui e no oci- 
dente. As fronteiras entre as escolas começaram a desaparecer impetuosamente, a linguagem unifica-se graças ao desenvolvimento de experiências e da prática. Por isso, hoje, no mundo, não existem autoridades absolutas, não há pessoas que estejam fora da crítica. Existem alguns poucos clássicos vivos, mas já bastante idosos, com quem se mantém uma relação especial. Mas a sua participação é bastante restrita. Agora os que são líderes verdadeiros são os primeiros entre todos os iguais. Isso é bem diferente do que havia em meados do século passado. Particularmente agora, nenhuma escola, nenhuma orientação, nenhuma teoria consegue sobreviver, no mundo moderno, sem interagir com outras teorias. Se ela tentar conservar a sua pureza, estará condenada. Essa é a posição que eu defendo hoje. Na teoria histórico-cultural e na teoria da atividade, há um potencial muito grande, mas esse potencial pode se revelar somente por meio da interação com outras teorias.

Ao ouvirmos suas palavras, minhas colegas e eu ponderamos que, de qualquer modo, as formulações de Vigotski são mais divulgadas e estudadas no ocidente do que a teoria da atividade, de Leontiev e, talvez, possa haver, no ocidente, uma tentativa de se proceder a uma espécie de destilação do viés marxista das obras de Vigotski. O Professor Dmitri formulou um ponto de vista interessante a esse respeito:

Entendo porque Vigotski. É uma escala maior: ele respondia às questões com que a psicologia ocidental se deparava, nos anos 70 e 80 . Mas ainda não havia questões, no ocidente, para as respostas que Leontiev oferecia. Nos anos 80 e 90, a psicologia ocidental começou a se curar da ignorância do papel da cultura e do meio social. As principais teorias que existiam no ocidente, até os anos 60, eram antagônicas. Isso era algo que precisava ser superado. Nos anos 70 isso começou a mudar, pois essa abordagem se esgotara. Teve início a compreensão de que o papel da cultura é bem mais sério. Então, descobriram Vigotski.

Quanto à questão do viés marxista, por um lado, tanto Vigotski quanto Leontiev eram marxistas sinceros; por outro, naquela época, pelas palavras e ideias de Marx, muita coisa vinha para a nossa psicologia e filosofia. Na realidade, seria mais preciso dizer que Vigotski não era tanto marxista, quanto espinosista, e Leontiev, não tão marxista quanto hegeliano, pois, no caso deste último, praticamente o que utiliza de Marx em suas ideias é o que este trouxe de Hegel, 
Vigotski e Leontiev...

que foi professor de Marx. Porém, naqueles tempos soviéticos, por muitos motivos, era muito mais cômodo referir-se a Marx do que a Hegel, ainda que fossem as mesmas ideias. Por exemplo, muitas ideias de Hegel eram referidas por meio de Lenin. $O$ trabalho de Lenin Os cadernos filosóficos é uma resenha de ideias de Hegel, mas as referências eram feitas a Lenin, quando, na verdade, este reescrevera as ideias de Hegel em seus Cadernos filosóficos. De fato, pelo marxismo vinha muita coisa boa. Marx era um pensador profundo e os cientistas da área das humanidades diferenciavam-se não por se referenciarem ou não a Marx, pois não existia essa diferença, já que todos se referiam a ele. A diferença estava em outro ponto. Alguns simplesmente enfeitavam trechos com as citações que consideravam necessárias e nada mais havia além disso. Mas havia aqueles que partiam do que encontravam em Marx, continuavam um pensamento, trabalhando e desenvolvendo suas ideias e concepções. O problema não é em quem você se apoia, mas o que você faz com isso dali para frente.

Concluída a conversa, ele nos apresentou a alguns de seus estudantes e colegas de trabalho, bem como nos presenteou com vários livros.

\section{REFERÊNCIAS BIBLIOGRÁFICAS}

BLANCK, G. Prefácio. In: VIGOTSKI, L. S. Psicologia pedagógica. Porto Alegre: Artmed, 2003. p. I5-32.

IAROCHEVSKI, M. G. L. S. Vigotski: v poiskakh novoi psikhologii. Moskva: URSS, 2007. KOZULIN, A. La psicologia de Vygotski. Madrid: Alianza Editorial, 1990.

LEONTIEV, A. A.; LEONTIEV, D. A.; SOKOLOVA, E. E. Aleksei Nikolaievitch Leontiev: deiatielnost, soznanie, litchnost. Moskva: Smisl, 2005.

LEVITIN, K. One is not born a personality. 1980. Disponível em: http://leninist.biz/en/I 982/ ONBP322/I.2-Ages.and.Days. Acesso em: 20 fev. 2008.

LURIA, A. R. Biographical note on L. S. Vygotsky. In: VYGOTSKY, L. S. Mind in society: the development of higher psychological processes. Massachusetts: Harvard University Press, 1979. p. I5-16.

Nota bibliográfica [sic] sobre L. S. Vygotsky. In: VYGOTSKY, L. S. A formação social da mente. São Paulo: Martins Fontes, 1984. [Trad. José Cipolla Neto, Luis Silveira Menna Barreto e Solange Castro Afeche. p. I7-18.] 
VIGODSKAIA, G. L.; LIFANOVA, T. M. Lev Semionovitch Vigotski: jizn, deiatelnost, chtrikhi k portretu. Moskva: Academia i Smisl, 1996.

VIGOTSKI., L. S. Psicologia pedagógica. Porto Alegre: Artmed, 2003.

Recebido em: março 2008

Aprovado para publicação em: maio 2008 